\title{
Assessment of health risk behaviours and their interrelationships among young people from two counties of Romania
}

\author{
Lucia Maria Lotrean • Valeria Laza • Carmen Ionut • \\ Hein de Vries
}

Received: 16 September 2009 /Accepted: 18 January 2010/Published online: 24 February 2010

(C) The Author(s) 2010. This article is published with open access at Springerlink.com

\begin{abstract}
Aim The first goal of this study was to assess the prevalence of different health risk behaviours among Romanian young people. Next, the interrelationship between different health risk behaviours as well as age and gender differences with respect to health risk behaviours were examined.

Subjects and methods Self-administered questionnaires were completed by a sample of 1,598 junior high school students, senior high school students and university students from urban and rural areas of two counties of Romania.

Results The results showed that $31 \%$ of junior high school students, $59.7 \%$ of senior high school students and $64.8 \%$ of university students reported more than one risk behaviour. Many of the risk behaviours were likely to correlate with each other and the strongest correlation was found between smoking, alcohol-related behaviour and precocious sexual intercourse. Factor analysis revealed that among junior high school students all health risk behaviours loaded on one factor. In senior high school students and university students the risk behaviours split into two factors, based probably on their frequency and severity. Factor 1 comprised smoking, alcohol-related behaviours as well as precocious sexual intercourse, while factor 2 included less
\end{abstract}

L. M. Lotrean $(\bowtie) \cdot$ V. Laza $\cdot$ C. Ionut

Department of Environmental Health,

University of Medicine and Pharmacy,

Primaverii 6/166,

Cluj-Napoca 400540, Romania

e-mail: llotrean@umfcluj.ro

H. de Vries

Department of Health Education and Promotion,

University of Maastricht,

Maastricht, The Netherlands common behaviours: violence, delinquency and illicit drug use. No gender differences were observed regarding the relationship between health risk behaviours.

Conclusion The results stress the importance of developing prevention programmes among Romanian youth for the behaviours discussed. Further research is needed to identify how to best offer these programmes: as stand-alone programmes or as an integrated set of programmes and whether the same approach has to be taken for younger and older adolescents.

Keywords Health risk behaviours · Romanian adolescents . Health education

\section{Introduction}

The leading causes of mortality and morbidity among young people can be traced to several preventable health risk behaviours that are often initiated during youth and may extend into adulthood (Brenner and Collins 1998; Kolip and Schmidt 1999; Lippe et al. 2008; Hibell et al. 2004). Many of these risk behaviours also contribute substantially to social problems such as family dysfunction, crime and school dropout (Grunbaum et al. 2004). Adolescence is a time of risk taking and experimentation and many studies have found a co-occurrence of several health risk behaviours among young people from different countries (BasenEngquist et al. 1996; Brener and Collins 1998; Bartlett et al. 2005; Mpofu et al. 2006). Several researchers also underlined that an early age at onset of health risk behaviours is associated with an increased likelihood that adolescents will engage in multiple risk behaviours as they progress through adolescence (Donovan and Jessor 1985; Jessor 1991; Brener and Collins 1998; Durant et al. 1999; Aarons 
et al. 1999; Paavola et al. 2004). Moreover, different studies showed that the relationship between several health risk behaviours varied across age groups (Kulbok and Cox 2002; Guilamo-Ramos et al. 2005).

Few studies described the distribution of health risk behaviours among Romanian young people; generally they restricted their investigations to a narrow range of problem behaviours such as substance use (Romanian Ministry of Health 2004; Abraham 2004; National Center for Chronic Disease Prevention and Health Promotion 2004) or sexual behaviour (Lotrean and Laza 2001; Romanian Ministry of Health 2005) or included only younger adolescents up to 15 years of age (Currie et al. 2008). The results of the European School Survey Project on Alcohol and Other Drugs carried out in Romania in 2003 showed that $64 \%$ of participating 16-year-old school students reported smoking at least once during their lifetime; an increase of $11 \%$ was noticed compared with the year 1999 . The same study shows that $52 \%$ of 16 -year-old school students have experimented with alcohol and experienced intoxication and 3\% have used cannabis at least once during their lifetime; when comparing with 1999, the prevalence of acute alcohol intoxication increased by $20 \%$, while the prevalence of cannabis use doubled (Romanian Ministry of Health 2004).

Moreover, as far as we know to date, no study has focused on the correlation between different health risk behaviours among Romanian adolescents. Through a greater understanding of the linkages between health risk behaviours among different groups of young people, we may increase our knowledge of how to develop integrative approaches leading to the adoption of a healthy lifestyle.

Hence, our study has three goals. The first goal is to assess the prevalence of a wide range of health risk behaviours among Romanian young people, starting with substance use and continuing with sexual behaviour, as well as violence and delinquency-related behaviours. The second goal concerns the description of cross-sectional interrelationships between different health risk behaviours. The third goal entails the analysis of age and gender differences with respect to health risk behaviours.

\section{Methods}

\section{Sample}

A cross-sectional study was conducted between November 2003 and February 2004 among 1,598 young people, aged 11-25 years, from two counties - Cluj and Hunedoarasituated in the north-western part of Romania. One city was selected from each county (Cluj-Napoca for Cluj county and Deva for Hunedoara county) and one rural area (Cuzdrioara and Criscior, respectively). In Romania the school system comprises four types of education levels: primary school (7- to 11-year-old students), junior high school or secondary school (age between 11 and 15 years), senior high school (age between 15 and 19 years) and university (students starting from 19 years of age).

In each of the two cities the study was performed in two junior high schools and in two senior high schools, which were randomly chosen. In the rural areas one junior high school and one senior high school were included in the study, since in these areas these were the only existing schools. In each of the selected high schools the study involved students from one to two classes of each grade level.

Consent to participate was obtained from the school administration, the standard procedure in Romania. The principals of the selected schools were contacted personally by one of the members of the research team and were approached regarding the participation in a survey investigating health-related behaviours of young people. All principals agreed to participate.

In Cluj-Napoca the study was also carried out among university students randomly chosen from 8 dorms belonging to the 4 main universities of the town: 40 girls and 40 boys living in the selected dorms were randomly chosen from each university. In Deva, the study involved 40 girls and 40 boys from the main town university, who were randomly chosen and asked to participate in the study during their university activity, because there were no dorms belonging to the university.

\section{Procedure}

All study subjects were asked to fill in an anonymous questionnaire, which took approximately $50 \mathrm{~min}$. Study procedures were designed to protect student anonymity and allow for voluntary participation. Among junior and senior high school students the questionnaire was administered and collected in the classroom by members of the research team. Teachers were present in the classroom during the data collection, but they stayed in the front of the class and they did not take part in collection of the questionnaires. No refusals were recorded; non-response was exclusively due to absence during the day of assessment. University students from Cluj-Napoca filled in the questionnaire in the dorm and university students from Deva filled it in at home; the researchers collected them afterwards. The refusal rate was low $(2.7 \%)$ and the students who refused to participate were replaced with students chosen from the same university.

\section{Questionnaire}

The study questionnaire was constructed using previously administered questions drawn from several sources, including the Global Youth Tobacco Survey (The Global Youth 
Tobacco Survey Collaborative Group 2002) and the Youth Risk Behavior Surveillance System (YRBSS) (National Center for Chronic Disease Prevention and Health Promotion 2003). Additional items were specifically developed for this survey. Question content included items related to demographics, as well as a broad range of healthy and unhealthy behaviours, the presence or absence of which may have immediate or long-term effects on the health status of adolescents and young adults. In a pilot test, the instrument was given to 90 Romanian junior high school, senior high school and university students to evaluate item clarity.

For this analysis we used 11 marker questions for health risk behaviours. Of these, 7 assessed substance use among study subjects: smoking during their lifetime $(0=$ no, $1=$ yes) and in the last month $(0=$ no, $1=$ yes $)$, use of alcohol $(0=$ never, $1=$ less than once per month, $2=$ monthly, but less than once per week, $3=$ at least one time per week), acute alcohol intoxication during their lifetime $(0=$ never, $1=$ once, $2=$ two or three times, $3=$ more than three times) and in the last month $(0=$ no, $1=$ yes $)$ as well as illicit drug use during their lifetime $(0=$ never, $1=$ once, $2=$ two or three times, $3=$ more than three times) and in the last month $(0=$ no, $1=$ yes $)$. Smoking behaviour was recorded in three categories $(0=$ never smoked, not even one puff, $1=$ smoked at least once during their lifetime, but not in the last month, $2=$ smoked in the last month) and alcohol acute intoxication and illicit drug use in five $(0=$ never experimented, $1=$ experimented once during their lifetime, but not in the last month, 2=experimented 2-3 times, but not in the last month, 3 =experimented more than three times, but not in the last month, $4=$ experimented in the last month).

Another two questions asked students if they started their sexual life $(0=$ they never had sexual intercourse, $1=$ they had engaged in sexual intercourse at least once during their lifetime) and age at beginning their sexual life; based on this, a new variable was created regarding precocious sexual intercourse $(0=$ no sexual life or beginning of sexual life after 18 years old, $1=$ first sexual intercourse before the age of 18). The last questions assessed students' involvement in a fight in the last month $(0=$ no, $1=$ once, $2=$ more than once $)$ and if they had ever stolen or destroyed other people's things $(0=$ never, $1=$ once, $2=$ a few times, $3=$ many times $)$.

The questionnaire for junior high school students did not include questions regarding illicit drug use and sexual behaviour, because many teachers considered them too sensitive for the younger age groups.

\section{Analyses}

The chi-square tests were used in order to evaluate the age and gender differences regarding the prevalence of different health risk behaviours.
In addition to examining single health risk behaviours, multiple risk behaviours were examined. The percentage of students who engaged in multiple risk behaviours was calculated by adding the number of the following risk behaviours reported by each student: (1) smoking at least once during their lifetime, (2) experimented with alcohol and experienced acute alcohol intoxication at least once during their lifetime, (3) used illicit drugs at least once during their lifetime, (4) precocious sexual intercourse, (5) participated in a physical fight in the last month and (6) destroyed or stole somebody's things at least once during their lifetime. Senior high school and university students could engage in zero to six risk behaviours, while junior high school students could engage in a maximum of four risk behaviours, because they were not asked any questions about sexual behaviour and illicit drug use. The mean number of multiple risk behaviours was also calculated and independent sample $t$ tests were used to assess the age and gender differences regarding the prevalence of multiple risk behaviours among the study subjects.

Bivariate correlations and factor analysis with oblimin rotation were used in order to examine the interrelationships between different health risk behaviours. According to Cohen, strong correlation was considered at $r>0.50$, while medium and small correlation was considered at $r>0.30$ and $r>0.10$, respectively.

Data analysis was performed with the SPSS 12 statistics programme. Significant results were reported at $p<0.05$.

\section{Results}

Prevalence of health risk behaviours

The study sample consisted of 630 junior high school students aged 11-15 years (324 boys and 306 girls, 498 from the urban area and 132 from the rural area), 568 senior high school students aged 15-19 years (281 boys and 287 girls, 325 from the urban area and 243 from the rural area) and 400 university students, aged 19-25 years (200 boys and 200 girls).

An overview of health risk behaviours by school enrolment is presented in Table 1. Overall, the prevalence of lifetime smoking was $52.1 \%$, with fewer junior high school students having tried tobacco smoking than senior high school students, while no significant difference was noticed between senior high school students and university students. The prevalence of tobacco smoking in the last month was $25 \%$ among study subjects and it increased significantly with age.

Experimentation with alcohol and experiencing intoxication during their lifetime as well as use of alcohol at least 
Table 1 Health risk behaviours among Romanian young people

\begin{tabular}{|c|c|c|c|c|}
\hline Health-related behaviours & $\begin{array}{l}\text { Total } \\
N=1,598^{\mathrm{d}} \\
\%\end{array}$ & $\begin{array}{l}\text { Junior high school } \\
N=630^{\mathrm{e}} \\
\%\end{array}$ & $\begin{array}{l}\text { Senior high school } \\
N=568^{\mathrm{f}} \\
\%\end{array}$ & $\begin{array}{l}\text { University } \\
N=400^{\mathrm{g}} \\
\%\end{array}$ \\
\hline Lifetime smoking & 52.1 & $30.6^{\mathrm{a}, \mathrm{b}}$ & 64.1 & 68.7 \\
\hline Smoking in the last month & 25 & $7.8^{\mathrm{a}, \mathrm{b}}$ & $32.2^{\mathrm{c}}$ & 42 \\
\hline Use of alcohol at least once per month & 50.4 & $31.3^{\mathrm{a}, \mathrm{b}}$ & $56^{\mathrm{c}}$ & 71.4 \\
\hline Alcohol intoxication at least once during lifetime & 50.2 & $31.5^{\mathrm{a}, \mathrm{b}}$ & $56.5^{\mathrm{c}}$ & 69.7 \\
\hline Alcohol intoxication in the last month & 5.3 & $2.3^{\mathrm{a}, \mathrm{b}}$ & 6 & 8.8 \\
\hline Use of illicit drugs during lifetime & $7.4^{\mathrm{h}}$ & NA & $3.7^{\mathrm{c}}$ & 12.7 \\
\hline Use of illicit drugs in the last month & $0.2^{\mathrm{h}}$ & NA & 0.2 & 0.3 \\
\hline Precocious sexual intercourse & $36.3^{\mathrm{h}}$ & NA & 38 & 33.8 \\
\hline Physical fight in the last month & 19.7 & $28.2^{\mathrm{a}, \mathrm{b}}$ & $18.0^{\mathrm{c}}$ & 8.4 \\
\hline Stealing or destroying other people's things during lifetime & 16.2 & $12.8^{\mathrm{b}}$ & $15.5^{\mathrm{c}}$ & 22.6 \\
\hline
\end{tabular}

$N A$ data are not available

${ }^{\text {a }}$ Statistically significant difference between junior and senior high school students $(p<0.05)$

${ }^{\mathrm{b}}$ Statistically significant difference between junior high school students and university students $(p<0.05)$

${ }^{\mathrm{c}}$ Statistically significant difference between senior high school students and university students $(p<0.05)$

${ }^{\mathrm{d}}$ The number varied between 1,598 and 1,544 due to missing answers to several questions

${ }^{\mathrm{e}}$ The number varied between 630 and 602 due to missing answers to several questions

${ }^{\mathrm{f}}$ The number varied between 568 and 561 due to missing answers to several questions

${ }^{g}$ The number varied between 400 and 381 due to missing answers to several questions

${ }^{\mathrm{h}}$ The percentages are calculated for university and senior high school students

once per month had quite the same prevalence as lifetime smoking in all three groups and, again, these behaviours increased significantly with age. Fewer students reported getting drunk in the last month than reported tobacco smoking in the last month, in all three groups. No difference was noticed between senior high school students and university students regarding alcohol intoxication in the last month.

The percentage of the study sample that declared they had stolen or destroyed things during their lifetime was $16.2 \%$ and this behaviour increased with age. Around $20 \%$ of the study subjects reported fighting in the last month and this behaviour was most frequent among junior high school students.

The percentage of students who reported having tried illegal drugs in the past was $7.4 \%$, with more university students reporting illegal drug use vs senior high school students. One third of senior high school students and university students reported having had sexual relations before the age of 18 , with no statistically significant differences between the two groups.

Table 2 presents the gender differences in the prevalence of health risk behaviours among all three groups of students. It shows that in all of the groups substance use, violence and stealing things during their lifetime were statistically significantly more frequent among boys than girls. The exception was smoking in the last month and lifetime use of drugs, where no gender differences were found among senior high school students. Precocious sexual intercourse was also more frequent among boys than girls both among senior high school students and university students.

Prevalence of multiple health risk behaviours

The prevalence of engaging in multiple risk behaviours is presented in Table 3 . Only $45.4 \%$ of junior high school students, $17.7 \%$ of senior high school students and $12.5 \%$ of university students were not engaged in any risk behaviour. The prevalence of multiple risk behaviours increased from $31 \%$ in junior high school students to $59.7 \%$ among senior high school students and $64.8 \%$ in university students. The mean number of risk behaviours was statistically significantly $(p<0.01)$ higher among senior high school students than among junior high school students (1.96 vs 1.03), while no significant difference was found between the senior high school and university students (1.96 vs 2.13).

More girls than boys had no engagement in health risk behaviours in all three groups (see Table 3). The mean number of health risk behaviours was significantly higher $(p<0.01)$ among boys than girls in junior high school $(1.31$ vs 0.75$)$, senior high school (2.41 vs 1.52$)$ as well as university students (2.61 vs 1.71 ). 
Table 2 Gender differences regarding health risk behaviours

\begin{tabular}{|c|c|c|c|c|c|c|}
\hline & \multicolumn{2}{|c|}{ Junior high school } & \multicolumn{2}{|c|}{ Senior high school } & \multicolumn{2}{|c|}{ University } \\
\hline & $\begin{array}{l}\text { Girls } \\
N=306^{\mathrm{a}} \\
\%\end{array}$ & $\begin{array}{l}\text { Boys } \\
N=324^{\mathrm{b}} \\
\%\end{array}$ & $\begin{array}{l}\text { Girls } \\
N=287^{\mathrm{c}} \\
\%\end{array}$ & $\begin{array}{l}\text { Boys } \\
N=281^{\mathrm{d}} \\
\%\end{array}$ & $\begin{array}{l}\text { Girls } \\
N=200^{\mathrm{e}} \\
\%\end{array}$ & $\begin{array}{l}\text { Boys } \\
N=200^{\mathrm{f}} \\
\%\end{array}$ \\
\hline Lifetime smoking & $24.5^{*}$ & 36.4 & $58.9 *$ & 69.4 & $63.5^{*}$ & 74 \\
\hline Smoking in the last month & $4.9^{*}$ & 10.5 & 30.3 & 34.2 & $34 *$ & 50 \\
\hline Use of alcohol at least once per month & $26.1 *$ & 36.5 & $42.4^{*}$ & 69.8 & $55.8^{*}$ & 86.9 \\
\hline Alcohol intoxication at least once during lifetime & $25.3 *$ & 37.2 & $42.9 *$ & 70.5 & $55.5^{*}$ & 84 \\
\hline Alcohol intoxication in the last month & $0.3 *$ & 4.2 & $2.4 *$ & 9.6 & $2^{*}$ & 15.5 \\
\hline Use of illicit drugs during lifetime & NA & NA & 2.4 & 5 & $7.6^{*}$ & 18.1 \\
\hline Use of illicit drugs in the last month & NA & NA & 0 & 0.4 & 0 & 0.5 \\
\hline Precocious sexual intercourse & NA & NA & $28.6^{*}$ & 47.7 & $18.5^{*}$ & 50.0 \\
\hline Physical fight in the last month & $17^{*}$ & 39.1 & $10.2 *$ & 26.3 & $4.5^{*}$ & 12.6 \\
\hline Stealing or destroying other people's things during lifetime & $8.1^{*}$ & 17.4 & $10.2 *$ & 21 & $21.1 *$ & 24.2 \\
\hline
\end{tabular}

NA data are not available

*Statistically significant difference between boys and girls $(p<0.05)$

${ }^{a}$ The number varied between 306 and 297 due to missing answers to several questions

${ }^{\mathrm{b}}$ The number varied between 324 and 301 due to missing answers to several questions

${ }^{\mathrm{c}}$ The number varied between 287 and 283 due to missing answers to several questions

${ }^{\mathrm{d}}$ The number varied between 281 and 274 due to missing answers to several questions

${ }^{\mathrm{e}}$ The number varied between 200 and 190 due to missing answers to several questions

${ }^{\mathrm{f}}$ The number varied between 200 and 182 due to missing answers to several questions

\section{Associations between health risk behaviours}

Table 4 presents the association between the studied health risk behaviours among the students. Among junior high school students all behaviours had low or moderate correlation with each other and the strongest correlation was between smoking, alcohol use and alcohol intoxication.

In senior high school and university students smoking and alcohol-related behaviours as well as precocious sexual intercourse were also moderately correlated. In both groups there was a statistically significant correlation between illicit drug use and smoking, alcohol-related behaviours and precocious sexual intercourse, but the correlation was low, except the moderate correlation between illicit drug use and alcohol intoxication.

The other two variables-fighting in the last month and destroying things - were correlated with each other in both senior high school students and university students. Among senior high school students, both variables were poorly correlated with all of the other behaviours, with the exception that no correlation was found between destroying things at least once during their lifetime and precocious beginning of sexual life. Among university students, fighting in the last month was poorly correlated with alcohol intoxication, illicit drug use and precocious beginning of sexual life. A similar situation was encountered for delinquency-related behaviour, except that no correlation was found with precocious sexual intercourse.

Running bivariate correlations separately for boys and girls within each of the three age groups showed similar results; no significant gender differences could be observed.

A factor analysis with oblimin rotation was used in order to examine the existence of related behaviours. Using eigenvalues greater than one resulted in a one-factor solution for junior high school students and in a twofactor solution for senior high school and university students. The results are presented in Table 5 for factor loading of 0.40 and greater.

Among junior high school students, the first factor was made of all problem behaviours assessed among them: smoking, alcohol use and alcohol intoxication, fighting in the last month and destroying things during their lifetime. Among both senior high school and university students the first factor comprised smoking, use of alcohol and alcohol intoxication as well as precocious beginning of sexual life, while in the second factor loaded illicit drug use, fighting in the last month and destroying other people's things. Alcohol intoxication loaded on both factors, but the loading was greater for factor 1 .

Factor analysis was done separately for boys and girls from each of the three groups and similar results were obtained; no different patterns for boys and girls were found. 
Table 3 Prevalence of multiple risk behaviours
${ }^{a}$ Due to missing answers to several questions, the number of students whose involvement in multiple risk behaviours could be assessed decreased

\begin{tabular}{|c|c|c|c|}
\hline Number of risk behaviours & Junior high school (\%) & Senior high school (\%) & University $(\%)$ \\
\hline Total & $N=581^{\mathrm{a}}$ & $N=558^{\mathrm{a}}$ & $N=375^{\mathrm{a}}$ \\
\hline 0 & 45.4 & 17.7 & 12.5 \\
\hline 1 & 23.6 & 22.6 & 22.7 \\
\hline 2 & 16.9 & 24.4 & 26.4 \\
\hline 3 & 10.3 & 21.3 & 22.9 \\
\hline 4 & 3.8 & 10.2 & 9.1 \\
\hline 5 & - & 2.7 & 5.1 \\
\hline 6 & - & 1.1 & 1.3 \\
\hline Girls & $N=291^{\mathrm{a}}$ & $N=285^{\mathrm{a}}$ & $N=198^{\mathrm{a}}$ \\
\hline 0 & 56.7 & 23.8 & 17.2 \\
\hline 1 & 22.7 & 28.8 & 30.3 \\
\hline 2 & 11.0 & 27.4 & 31.3 \\
\hline 3 & 7.2 & 13.0 & 10.6 \\
\hline 4 & 2.4 & 4.9 & 6.6 \\
\hline 5 & - & 1.8 & 3.5 \\
\hline 6 & - & 0.3 & 0.5 \\
\hline Boys & $N=290^{\mathrm{a}}$ & $N=273^{\mathrm{a}}$ & $N=177^{\mathrm{a}}$ \\
\hline 0 & 34.1 & 11.4 & 7.3 \\
\hline 1 & 24.5 & 16.1 & 14.1 \\
\hline 2 & 22.8 & 21.2 & 20.9 \\
\hline 3 & 13.4 & 30.0 & 36.7 \\
\hline 4 & 5.2 & 15.8 & 11.9 \\
\hline 5 & - & 3.7 & 6.8 \\
\hline 6 & - & 1.8 & 2.3 \\
\hline
\end{tabular}

\section{Discussion}

The results of the study show that many Romanian junior and senior high school as well as university students from our study sample engage in behaviours that place them at risk for health and social problems. Consistent with previous studies (Paavola et al. 2004; Ellickson et al. 2001; Lazcano-Ponce et al. 2003; Sutherland and Shepherd 2001), the likelihood of involvement in risk behaviours, such as substance use, increased with age, while some risks, particularly violencerelated, tended to be replaced rather than compounded over time (Brenner and Collins 1998; Hibell et al. 2004).

Similar to other research results, many health risk behaviours were found to be interrelated rather than being a collection of independent activities (Brenner and Collins 1998; Potthoff et al. 1998; Fetro et al. 2001; Anteghini et al. 2001; Shrier et al. 1997). Almost one third of the junior high school students and around $60 \%$ of the senior high school as well as university students were involved in more than one risk behaviour. This shows that engagement in multiple risk behaviours starts in junior high school and increases with age, being already well established in senior high school.

Furthermore, we found that various health risk behaviours correlated. The strongest correlation was between smoking and alcohol-related behaviours in junior high school students and between smoking, alcohol and sexrelated behaviours in senior high school and university students. This type of interrelationship is also documented by studies from other countries (Takakura et al. 2001; Everett et al. 2000; Anteghini et al. 2001; Shrier et al. 1997; Cooper 2002). There were also correlations between other health risk behaviours (e.g. between illicit drug use and violence and delinquency-related behaviours or between illicit drug use, smoking and alcohol abuse), but weaker.

Factor analysis was used to further examine the relationship among health risk behaviours. Several previous studies showed that a single common factor accounted for the positive correlations among a number of adolescent problem behaviours (Donovan and Jessor 1985; Jessor 1991). The results of the factor analysis in our study revealed that for junior high school students, no clear differentiation seemed to exist between health risk behaviours. This may suggest that at this age students involved in one risk behaviour are at greater risk of becoming involved in other health risk behaviours as well.

There were also studies that found that health risk behaviours are multidimensional, but the examined behaviours, as well as the precise number of dimensions involved and their behavioural content, varied between studies (Basen- 
Table 4 Bivariate correlations* between health risk behaviours

\begin{tabular}{|c|c|c|c|c|c|c|}
\hline & Smoking & Alcohol use & Alcohol intoxication & Illicit drug use & Precocious sexual intercourse & Fighting last month \\
\hline \multicolumn{7}{|c|}{ Alcohol use } \\
\hline 1 & 0.27 & & & & & \\
\hline 2 & 0.35 & & & & & \\
\hline 3 & 0.36 & & & & & \\
\hline \multicolumn{7}{|c|}{ Alcohol intoxication } \\
\hline 1 & 0.37 & 0.40 & & & & \\
\hline 2 & 0.41 & 0.51 & & & & \\
\hline 3 & 0.40 & 0.49 & & & & \\
\hline \multicolumn{7}{|c|}{ Illicit drug use } \\
\hline 1 & NA & NA & NA & & & \\
\hline 2 & 0.18 & 0.15 & 0.27 & & & \\
\hline 3 & 0.22 & 0.23 & 0.36 & & & \\
\hline \multicolumn{7}{|c|}{ Precocious sexual intercourse } \\
\hline 1 & NA & NA & NA & NA & & \\
\hline 2 & 0.33 & 0.22 & 0.35 & 0.12 & & \\
\hline 3 & 0.39 & 0.37 & 0.44 & 0.19 & & \\
\hline \multicolumn{7}{|c|}{ Fighting last month } \\
\hline 1 & 0.24 & 0.22 & 0.34 & NA & NA & \\
\hline 2 & 0.12 & 0.24 & 0.29 & 0.17 & 0.16 & \\
\hline 3 & NS & NS & 0.24 & 0.23 & 0.12 & \\
\hline \multicolumn{7}{|c|}{ Destroying things } \\
\hline 1 & 0.20 & 0.14 & 0.22 & NA & NA & 0.22 \\
\hline 2 & 0.13 & 0.14 & 0.21 & 0.19 & NS & 0.19 \\
\hline 3 & NS & NS & 0.25 & 0.25 & NS & 0.17 \\
\hline
\end{tabular}

$N A$ data are not available, NS non-significant, 1 junior high school, 2 senior high school, 3 university

*All correlations with depicted correlation coefficient are significant: $p<0.05$

Engquist et al. 1996; Ebin et al. 2001; Takakura et al. 2001; Kulbok and Cox 2002; Bartlett et al. 2005). This pattern was found in our study among senior high school students and university students where we identified two factors. Similar to other studies (Ebin et al. 2001) we interpret factors 1 and 2 as distinguishing between common and uncommon engagement in problem behaviours. Factor 1 comprised smoking, use of alcohol and alcohol intoxication as well as precocious sexual intercourse, behaviours, which were most frequently encountered and which are possibly part of the normal experimentation period that often characterizes adolescent behaviour at this age. Factor 2 included less common behaviours among the study subjects (violence, delinquency, illicit drug use), which may have more severe consequences regardless of the developmental stage.

Several studies showed that gender differences with regard to health risk behaviours vary within countries and regions (Hibell et al. 2004; Currie 2004). If, traditionally,
Table 5 Results of the factor analysis

$N A$ data are not available

\begin{tabular}{|c|c|c|c|c|c|}
\hline \multirow[t]{2}{*}{ Behaviour } & \multirow{2}{*}{$\begin{array}{l}\text { Junior high school } \\
\text { Factor } 1\end{array}$} & \multicolumn{2}{|c|}{ Senior high school } & \multicolumn{2}{|c|}{ University } \\
\hline & & Factor 1 & Factor 2 & Factor 1 & Factor 2 \\
\hline Smoking & 0.66 & 0.74 & & 0.72 & \\
\hline Alcohol use & 0.64 & 0.70 & & 0.73 & \\
\hline Alcohol intoxication & 0.76 & 0.75 & 0.48 & 0.74 & 0.50 \\
\hline Illicit drug use & NA & & 0.64 & & 0.66 \\
\hline Precocious sexual intercourse & NA & 0.67 & & 0.73 & \\
\hline Fighting last month & 0.62 & & 0.61 & & 0.62 \\
\hline Destroying things & 0.49 & & 0.73 & & 0.73 \\
\hline
\end{tabular}


young boys were more often engaged in risk behaviours than girls, in some countries the differences dissipated (The Global Youth Tobacco Survey Collaborative Group 2002; Hibell et al. 2004; Currie 2004). In our study, in all three groups, health risk behaviours were generally more frequent among boys than girls, but no significant gender differences were found with regard to the relationship between health-compromising behaviours.

The findings in this study have several implications for public health professionals, health educators and researchers. First, given the age-related changes seen in health risk behaviours, health promotion intervention for Romanian young people must be sensitive to developmental changes and appropriately timed. Additional research is needed to better understand the appropriate type and timing of interventions as well as the content of messages to address several health risk behaviours.

Second, the association between several health risk behaviours among Romanian adolescents from our sample raises the question of whether to address the promotion of healthy lifestyles among youth in one overall programme or by dealing with them as separate topics and whether the same approach has to be taken for younger and older adolescents. As other studies suggested (Neumark-Sztainer et al. 1997; Takakura et al. 2001), the categorization of behaviours into factors could assist in designing and implementing appropriate health promotion interventions among young people, helping to better address the range of health-related behaviours among them. Hence, focusing on behaviours, such as illicit drug use, without also addressing other related behaviours, such as violence or delinquency, may be less effective than health education programmes that are comprehensive. At the same time, a combination of smoking prevention programmes with activities, which prevent alcohol abuse or promote a healthy sexual behaviour, could be also more effective than programmes, which are focused only on one type of behaviour. However, the advantages and disadvantages of more generic programmes are not clear at this time (Wetzels et al. 2003; Flay et al. 2004; Werch et al. 2005). In order to draw any conclusions regarding how these behaviours should best be addressed, intervention studies are necessary, in which different approaches are compared.

Third, similar to other studies (Neumark-Sztainer et al. 1997; Currie 2004), our results show the importance of identifying high-risk youth and targeting them with comprehensive prevention programmes. Creative ways of reaching high-risk youth need to be considered, both regarding the types of messages offered and settings for health promotion intervention programmes. Furthermore, this study suggests that prevention efforts aimed at high-risk youth during early adolescence need such a multi-problem focus, because this co-occurrence of problem behaviours is already evident among junior high school students.
Fourth, no important differences with regard to the relationship between health risk behaviours were found between boys and girls, suggesting that the content of the comprehensive health promotion programmes needs no gender-specific approach.

Fifth, health care providers must also be aware of the interrelationship existing between health risk behaviours in order to identify, treat and prevent them correctly. Such an approach has been successfully used to identify probable substance use among smoking pregnant adolescent girls (Archie et al. 1997).

This study is subject to limitations. First, due to its crosssectional nature, the associations reported here should be interpreted with caution and nothing may be assumed about causality or temporal precedence. Second, the conclusions are based on a sample of 1,598 young people from both the rural and urban areas of two counties of Romania, but it is inevitably a limit to the generalization of the study findings beyond this sample. Third, this study involved junior and senior high school students as well as university students, but no adolescents who dropped out of school and are probably more likely to engage in health risk behaviours. Moreover, in Cluj-Napoca the study included only university students from university dorms. Hence, future studies should use national representative samples and must try to include out of school young people as well. Fourth, another common limitation with most studies on this topic is the reliance on adolescents' self-reports. Although some respondents may not report truthfully, the likelihood of honest responses is maximized in this survey by conducting it anonymously.

In spite of these limitations, the current study is probably the first research project that assessed the relationship existing between different health risk behaviours among Romanian youth. It confirms the complexity of Romanian adolescents' health risk behaviours and shows the necessity of future research in this area in order to develop appropriate health promotion interventions.

Acknowledgement The study was performed at the Faculty of Health, Medicine and Life Science (FHML), Maastricht University, Care and Public Health Research Institute (Caphri).

The study was funded by the grant 33382/2004 from CNCSIS, Romania and by a Huygens scholarship offered by the Netherlands Organization for International Cooperation in Higher Education.

The authors would like to thank all teachers and students involved in the project.

Conflict of interest None.

Open Access This article is distributed under the terms of the Creative Commons Attribution Noncommercial License which permits any noncommercial use, distribution, and reproduction in any medium, provided the original author(s) and source are credited. 


\section{References}

Aarons GA, Brown SA, Coe MT, Myers MG, Garland AF, EzzetLofstram R, Hazen AL, Hough RL (1999) Adolescent alcohol and drug abuse and health. J Adolesc Health 24:412-421

Abraham P (2004) Prevalenta consumului de droguri in Romania, 2004. (Prevalence of drug use in Romania, 2004). National Agency against Drugs, Bucharest

Anteghini M, Fonseca H, Ireland M, Blum RW (2001) Health risk behaviors and associated risk and protective factors among Brazilian adolescents in Santos, Brazil. J Adolesc Health 28:295-302

Archie CL, Anderson MM, Gruber EL (1997) Positive smoking history as a preliminary screening device for substance use in pregnant adolescents. J Pediatr Adolesc Gynecol 10:13-17

Bartlett R, Holditch-Davis D, Belyea M (2005) Clusters of problem behaviors in adolescents. Res Nurs Health 28:230-239

Basen-Engquist K, Edmundson EW, Parcel GS (1996) Structure of health risk behavior among high school students. J Consult Clin Psychol 64:764-775

Brener N, Collins J (1998) Co-occurrence of health-risk behaviors among adolescents in the United States. J Adolesc Health 22:209-13

Cooper ML (2002) Alcohol use and risky sexual behavior among college students and youth: evaluating the evidence. J Stud Alcohol Suppl 14:101-117

Currie C (2004) Young people's health in context: international report from the HBSC 2001/02 survey. WHO Regional Office for Europe, Copenhagen

Currie C (2008) Inequalities in young people's health: international report from the HBSC 2005/06 survey. WHO Regional Office for Europe, Copenhagen

Donovan JE, Jessor R (1985) Structure of problem behavior in adolescence and young adulthood. J Consult Clin Psychol 53:890-904

DuRant RH, Smith JA, Kreiter SR, Krowchuk DP (1999) The relationship between early age of onset of initial substance use and engaging in multiple health risk behaviors among young adolescents. Arch Pediatr Adolesc Med 153:286-291

Ebin VJ, Sneed CD, Morisky DE, Rotheram-Borus MJ, Magnusson AM, Malotte CK (2001) Acculturation and interrelationships between problem and health-promoting behaviors among Latino adolescents. J Adolesc Health 28:62-72

Ellickson PL, Tucker JS, Klein DJ (2001) High-risk behaviors associated with early smoking: results from a 5-year follow-up. J Adolesc Health 28:465-473

Everett SA, Malarcher AM, Sharp DJ, Husten CG, Giovino GA (2000) Relationship between cigarette, smokeless tobacco, and cigar use, and other health risk behaviors among U.S. high school students. J Sch Health 70:234-240

Fetro JV, Coyle KK, Pham P (2001) Health-risk behaviors among middle school students in a large majority-minority district. J Sch Health 71:30-37

Flay BR, Graumlich S, Segawa E, Burns JL, Holliday MY, Aban Aya Investigators (2004) Effects of 2 prevention programs on highrisk behaviors among African American youth: a randomized trial. Arch Pediatr Adolesc Med 158:377-384

Grunbaum JA, Kann L, Kinchen S, Ross S, Hawkins J et al (2004) Youth risk behavior surveillance-United States, 2003. MMWR Surveill Summ 53:1-96

Guilamo-Ramos V, Litardo HA, Jaccard J (2005) Prevention programs for reducing adolescent problem behaviors: implications of the co-occurrence of problem behaviors in adolescence. J Adolesc Health $36: 82-86$
Hibell B, Andersson B, Bjarnason T, The ESPAD Report 2003 et al (2004) Alcohol and other drug use among students in 35 European countries. The Swedish Council for Information on Alcohol and Other Drugs (CAN) and the Pompidou Group at the Council of Europe, Stockholm

Jessor R (1991) Risk behavior in adolescence: a psychosocial framework for understanding and action. J Adolesc Health 12:597-605

Kolip P, Schmidt B (1999) Gender and health in adolescence. WHO Regional Office for Europe, Copenhagen

Kulbok PA, Cox CL (2002) Dimensions of adolescent health behavior. J Adolesc Health 31:394-400

Lazcano-Ponce EC, Hernández B, Cruz-Valdez A et al (2003) Chronic disease risk factors among healthy adolescents attending public schools in the state of Morelos, Mexico. Arch Med Res 34:222-236

Lippe J, Brener N, Kann L, Kinchen S, Harris W, McManus T et al (2008) Youth risk behavior surveillance-Pacific Island United States Territories, 2007. MMWR Surveill Summ 57:28-56

Lotrean LM, Laza V (2001) Knowledge, attitude and behaviour of students of a Romanian university centre concerning HIV/AIDS. CEJOEM 7:45-52

Mpofu E, Caldwell L, Smith E, Flisher AJ, Mathews C, Wegner L, Vergnani T (2006) Rasch modeling of the structure of health risk behavior in South african adolescents. J Appl Meas 7:323-334

National Center for Chronic Disease Prevention and Health Promotion (2003) YRBSS: Youth risk behavior surveillance system. http:// www.cdc.gov/healthyyouth/yrbs/trends.htm. Accessed Mar 2003

National Center for Chronic Disease Prevention and Health Promotion (2004) Global youth tobacco survey. http://www.cdc.gov/tobacco/ global/GYTS/factsheets/2004/pdf/Romania_factsheet2004.pdf. Accessed Feb 2006

Neumark-Sztainer D, Story M, Toporoff E, Himes JH, Resnick MD, Blum RW (1997) Covariations of eating behaviors with other health-related behaviors among adolescents. J Adolesc Health 20:450-458

Paavola M, Vartiainen E, Haukkala A (2004) Smoking, alcohol use, and physical activity: a 13-year longitudinal study ranging from adolescence into adulthood. J Adolesc Health 35:238-244

Potthoff SJ, Bearinger LH, Skay CL, Cassuto N, Blum RW, Resnick MD (1998) Dimensions of risk behaviors among American Indian youth. Arch Pediatr Adolesc Med 152:157-163

Romanian Ministry of Health (2004) The European School Survey Project on alcohol and other drugs. The Ministry, Bucharest

Romanian Ministry of Health (2005) Studiul sanatatii reproducerii: Romania 2004. (Study of sexual health: Romania, 2004). Romanian Ministry of Health, Bucharest

Shrier LA, Emans J, Woods ER, DuRant RH (1997) The association of sexual risk behaviors and problem drug behaviors in high school students. J Adolesc Health 20:377-383

Sutherland I, Shepherd JP (2001) The prevalence of alcohol, cigarette and illicit drug use in a stratified sample of English adolescents. Addiction 96:637-640

Takakura M, Nagayama T, Sakihara S, Willcox C (2001) Patterns of health-risk behavior among Japanese high school students. J Sch Health 71:23-29

The Global Youth Tobacco Survey Collaborative Group (2002) Tobacco use among youth: a cross country comparison. Tob Control 11:252-270

Werch CE, Moore MJ, Diclemente CC et al (2005) Single vs. multiple drug prevention: is more always better?: a pilot study. Subst Use Misuse 40:1085-1010

Wetzels JJL, Kremers SPJ, Vitória PD, de Vries H (2003) The alcoholtobacco relationship: a prospective study among adolescents in six European countries. Addiction 98:1755-1763 